\title{
Laparoscopic transabdominal isthmic cerclage in a case of cervical agenesis and a successful pregnancy with ICSI
}

Received: 8 March 2006 / Accepted: 6 May 2006 / Published online: 27 July 2006

(C) Springer-Verlag Berlin / Heidelberg 2006

\begin{abstract}
The objective was to construct a laparoscopic transabdominal isthmic cerclage in a patient with cervical agenesis at Kadir Has University, Metropolitan Florence Nightingale Hospital. A 39-year-old woman diagnosed with primary infertility due to cervical agenesis was admitted to our hospital because of recurrent assisted reproductive technique (ART) failures. She underwent three operations for acute abdominal pain due to endometriosis and pyometra. There was a tiny fistula-like opening at the level of the isthmus, through which menstrual blood passed. Three intracytoplasmic sperm injection (ICSI) attempts with transmyometrial transfer had failed at three different IVF centres. We performed a laparoscopic transabdominal isthmic cerclage to prevent a miscarriage due to a clinical condition similar to cervical insufficiency and then an ICSI procedure was performed. We delivered a healthy baby weighing 3,200 g by Caesarean section. We left the cerclage in place for subsequent pregnancies. To the best of our knowledge, this is the first report of laparoscopic isthmic cerclage for the prevention of a clinical condition similar to cervical insufficiency in cervical agenesis that has resulted in a term pregnancy after ICSI.
\end{abstract}

Keywords Laparoscopic cerclage - Abdominal cerclage · Cervical agenesis $\cdot$ Cervical insufficiency $\cdot$ ICSI

\section{Introduction}

Cervical incompetence has been acknowledged as a significant entity predisposing patients to second trimester miscarriage. Various surgical techniques have been used to prolong pregnancy and improve prenatal outcome. These

Y. Karaman $\cdot$ B. Bingol $(\bowtie) \cdot$ Z. Günenc

Kadir Has University,

Metropolitan Florence Nightingale Hospital,

Cemil Aslan Guder Sok No: 8,

Gayrettepe, Istanbul, Turkey

e-mail: banubingol1975@yahoo.com include transvaginal and transabdominal cervical cerclage applied preconceptionally or during pregnancy.

Here we report a case of 39-year-old-woman with cervical agenesis and infertility, in which laparoscopic isthmic placement of cerclage was performed before embryo transfer, resulting in a successful pregnancy.

\section{Case report}

A 39-year-old woman was admitted to our hospital with the diagnosis of primary infertility. When she was 15 years old, she consulted a gynaecologist because of acute abdominal pain. In her gynaecological examination, the cervix uteri could not be visualised and in the ultrasonographic examination bilateral endometriomas and haematometra were seen. A laparotomic cystectomy was performed and an incision was made at the level of the isthmus to let menstrual bleeding occur. During her reproductive period, she suffered from acute abdominal pain and she underwent three operations for pyometra and haematometra, and the incision was repeated for patency of the blocked passage. She had been married for 20 years and was unable to achieve a spontaneous pregnancy. In 1999, the couple attended an infertility clinic and her husband's spermiogram revealed severe oligospermia. In her gynaecologic examination, the cervix could not be visualised and it was noted that the vaginal cuff had a post-hysterectomy appearance. A diagnostic laparoscopy was carried out and severe adhesions were reported because of endometriosis and laparotomies. Three cycles of intracytoplasmic sperm injection (ICSI) and transmyometrial embryo transfer were performed. Although three or four embryos of good quality were transferred at every attempt, pregnancy was not achieved. In a university hospital, it was concluded that the couple could never have a baby because of cervical agenesis.

The patient was evaluated at our centre in January 2004. We performed a gynaecologic examination, but were unable to see the cervix. We invited the patient to be reexamined at the beginning of her menstrual period in order 
to see where the blood was going. She had severe dysmenorrhoea because of the narrow opening at the right side of the vaginal end. The fistula-like opening probably occurred because of the repeated incisions at the level of the isthmus. We decided to place an isthmic cerclage before IVF for a successful outcome.

Under general anaesthesia, the patient was placed in the dorsal lithotomy position, and a Foley catheter was inserted. The anterior vaginal wall neighbouring this narrow passage was grasped with a tenaculum and the passage was dilated with an 8-mm Hegar bougie under ultrasound and laparoscopic guidance. The Hegar bougie was placed and secured with a tenaculum and was not removed during the operation (Fig. 1). Then a laparoscopy was performed with three puncture sites, using the umbilical one for the laparoscope. The second and third ones were made in the suprapubic area. At the beginning of the surgical procedure, the adhesions were lysed using a $\mathrm{CO}_{2}$ laser and then the uterovesical peritoneum was incised transversely again with the laser, where the reflection of the bladder was seen. A non-absorbable prolene suture (No 2, Ethicon; Johnson \& Johnson, Istanbul, Turkey) was used. When the vesico-uterine space was opened, the bladder was pushed down. The ligature was passed through from the anterior and towards the posterior parts of the isthmus, and it was knotted at the level of the sacro-uterine ligaments.

After confirming that the ligature was in an appropriate place at the isthmus, the ends of the ligature were knotted. The peritoneum was sutured over the knot and the laparoscopy was finalised following haemostasis. The suture was left in place for subsequent pregnancies.

Two months later, we started controlled ovarian stimulation with recombinant follicle stimulating hormone (FSH; Puregon; Organon, Altunizade, Turkey) at 200 IU/day. We obtained 20 oocytes and 14 of them were metaphase II. We transferred two embryos on the 3rd day; both of them were reported to be Grade 1. The beta human chorionic gonadotrophin (HCG) level on the 11th day of embryo transfer was $223 \mathrm{mIU} / \mathrm{ml}$. During pregnancy, in the $32 \mathrm{nd}$
Fig. 1 The steps of laparoscopic transabdominal isthmic cerclage
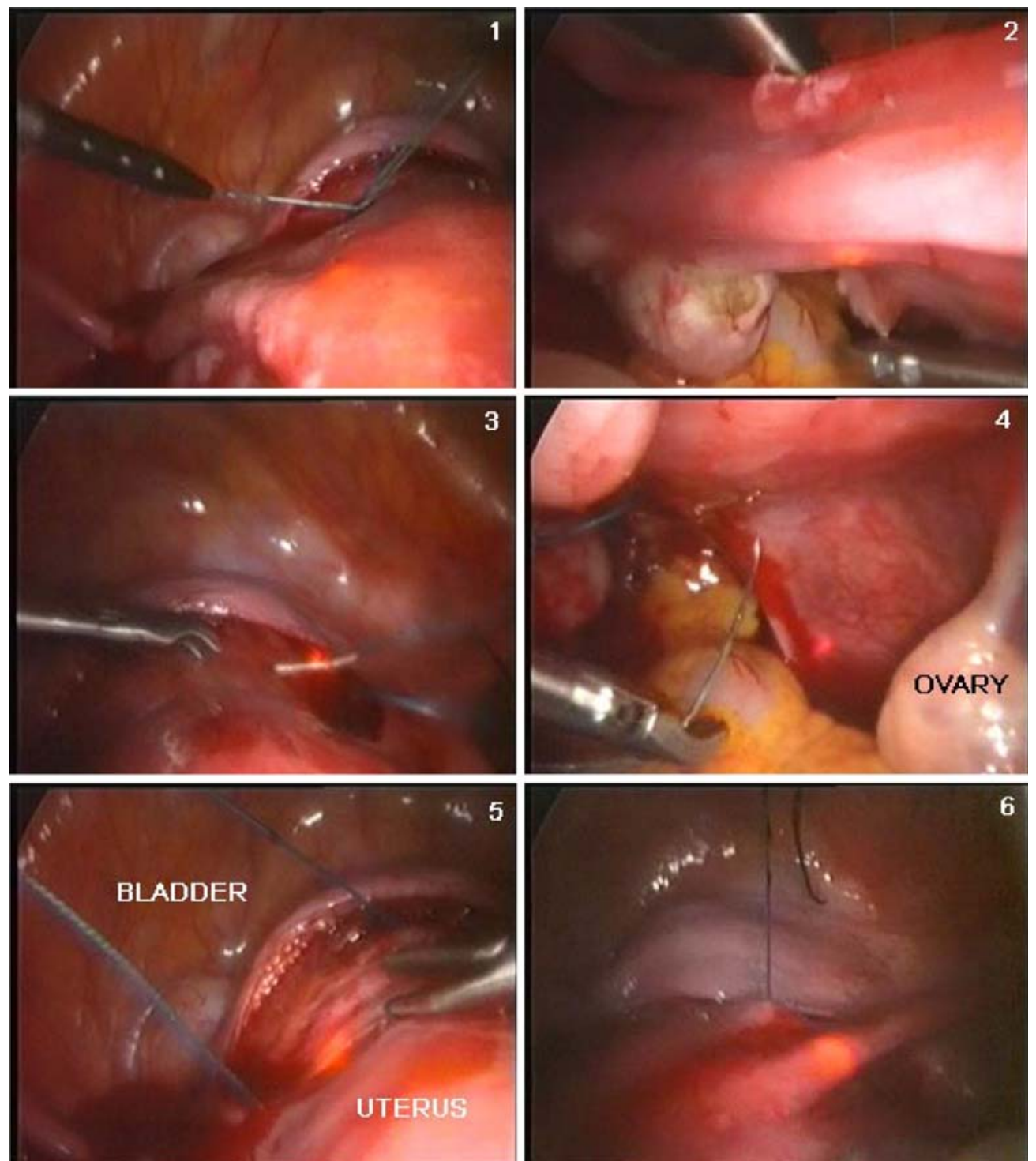
gestational week, there was a risk of pre-term labour, after which only bed rest was recommended. The antenatal follow-up showed no abnormality and she delivered a healthy male baby weighing $3,200 \mathrm{~g}$ in the 38th gestational week by Caesarean section.

\section{Discussion}

Cervical incompetence is a premature dilatation of the cervix leading to recurrent mid-trimester pregnancy loss or early premature labour. It is thought that the condition is caused by a defect in the strength of the cervical tissue either congenitally or acquired, resulting in the inability to maintain a pregnancy [1]. The treatment consists of placing a purse string suture around the cervix. The conventional method is placing the sutures vaginally, but it might not be possible in extremely short, deformed and scarred cervices or in the absence of a cervix. Abdominal cerclage has been advocated by several authors to overcome this problem.

The indications for abdominal cerclage are as follows: congenitally short cervix, extensively amputated cervix, marked scarring of the cervix, deep and jagged multiple cervical defects, and previously failed vaginal cerclage [2]. There are no studies in the literature showing that cervical agenesis always results in cervical insufficiency; however, an endoscopic cerclage operation was performed in our patient, since she had undergone several operations for haematometra and there was irregular fistula formation at the level of the isthmus, which could be a reason for a second trimester miscarriage. A review of the literature is shown in Table 1.

In 1965, Benson and Durfee first described the transabdominal cervico-isthmic cerclage by laparotomy in a group of women with cervical incompetence in whom a conventional transvaginal procedure was impossible [3]. Since then, these operations have been performed during pregnancy or before conception to prevent cervical insufficiency $[4,5]$. A less invasive approach is laparoscopic abdominal cerclage, which has the advantages of a laparoscopic procedure including no hospitalisation, less postoperative pain, and faster recovery [2].

In 1998, Scibetta and colleagues described the first case of the successful use of an interval laparoscopic technique for transabdominal cerclage placement, so as to avoid the need to resort to a laparotomy during the pregnant or nonpregnant state [6], but this case and all subsequent cases had normal cervical anatomy.

Gallot and colleagues reported the use of laparoscopic transabdominal cerclage in three women with a history of recurrent miscarriages and failed cerclage. All procedures were successful and two of them became pregnant within 4 months, delivering by Caesarean section at 38 weeks' gestation [7].

\section{Conclusion}

In the case presented, the failure of previous assisted reproductive technique (ART) cycles can be attributed to transmyometrial transfer, which caused bleeding. We created an artificial cervical canal through which we carried out the transfer of the embryos. There is only one study in the literature reporting transvaginal cerclage being performed in cases of severe cervical hypoplasia under ultrasound guidance [8]. To the best of our knowledge, this is the first report of transabdominal laparoscopic isthmic cerclage performed for cervical agenesis that has resulted in a successful pregnancy and a healthy baby following ICSI.

Table 1 Reproductive outcomes after laparoscopic abdominal cerclage

\begin{tabular}{|c|c|c|c|c|c|}
\hline Authors & $\begin{array}{l}\text { Number of } \\
\text { Cases }\end{array}$ & $\begin{array}{l}\text { Age } \\
\text { (years) }\end{array}$ & $\begin{array}{l}\text { Cerclage in } \\
\text { pregnancy }\end{array}$ & Indication & Pregnancy outcome \\
\hline $\begin{array}{l}\text { Al-Fadhli and } \\
\text { Tulandi [2] }\end{array}$ & 2 & 36,38 & No & Failed cerclages & $\begin{array}{l}\text { One term pregnancy, one not } \\
\text { pregnant }\end{array}$ \\
\hline $\begin{array}{l}\text { Darwish and } \\
\text { Hassan [9] }\end{array}$ & 1 & 31 & Yes & Eight failed cervical cerclages & Live birth, 37 weeks \\
\hline Gallot et al [7] & 3 & $\begin{array}{l}26,35 \\
29\end{array}$ & No & Failed cervical cerclages & $\begin{array}{l}\text { Two live births at } 38 \text { weeks; one } \\
\text { not pregnant }\end{array}$ \\
\hline $\begin{array}{l}\text { Henricus et al. } \\
{[10]}\end{array}$ & 1 & 34 & No & $\begin{array}{l}\text { Short cervix after wide excision followed by } \\
\text { immature delivery }\end{array}$ & $\begin{array}{l}\text { Live baby with intrauterine growth } \\
\text { restriction, } 37 \text { weeks }\end{array}$ \\
\hline $\begin{array}{l}\text { Ind and Mason } \\
{[11]}\end{array}$ & 1 & 33 & No & Two failed cervical cerclages & Not reported \\
\hline Lessor et al [12] & 1 & 40 & Yes & $\begin{array}{l}\text { Failed cerclage, diethylstilbestrol exposed, and } \\
\text { mid-trimester miscarriage }\end{array}$ & Live birth, 35 weeks \\
\hline $\begin{array}{l}\text { Mingione et al. } \\
{[4]}\end{array}$ & 11 & $22-39$ & No & $\begin{array}{l}\text { Absent or short cervix or failed cervical } \\
\text { cerclages }\end{array}$ & $\begin{array}{l}\text { Ten term live births, one elective } \\
\text { delivery at } 34.5 \text { weeks }\end{array}$ \\
\hline Scibetta et al. [6] & 1 & 37 & Yes & Absence of exocervix following cone biopsy & Live birth, 38.5 weeks \\
\hline Present case & 1 & 39 & No & Cervical agenesis & Live birth, 38.5 weeks \\
\hline
\end{tabular}


Acknowledgement We thank Russell Fraser for checking the English of this manuscript.

\section{References}

1. Ludmir J (1998) Sonographic detection of cervical incompetence. Clin Obstet Gynecol 31:101-109

2. Al-Fadhli R, Tulandi T (2004) Laparoscopic abdominal cerclage. Obstet Gynecol Clin North Am 31:497-504

3. Benson RC, Durfee RB (1965) Transabdominal cervicouterine cerclage during pregnancy for the treatment of cervical incompetency. Obstet Gynecol 25:145-155

4. Mingione MJ, Scibetta JJ, Sanko SR, Phipps WR (2003) Clinical outcomes following interval laparoscopic transabdominal cervico-isthmic cerclage placement: case series. Hum Reprod 18:1716-1719

5. Groom KM, Jones BA, Edmonds DK, Bennett PR (2004) Preconception transabdominal cervicoisthmic cerclage. Am J Obstet Gynecol 191:230-234
6. Scibetta JJ, Sanko SR, Phipps WR (1998) Laparoscopic transabdominal cervicoisthmic cerclage. Fertil Steril 69:161163

7. Gallot D, Savary D, Laurichesse H, Bournazeau JA, Amblard J, Lemery D (2003) Experience with three cases of laparoscopic transabdominal cervico-isthmic cerclage and two subsequent pregnancies. BJOG 110:696-700

8. Ludmir J, Jackson GM, Samuels P (1991) Transvaginal cerclage under ultrasound guidance in cases of severe cervical hypoplasia. Obstet Gynecol 78:1067-1072

9. Darwish A, Hassan Z (2002) Feasibility of laparoscopic abdominal cerclage in the second trimester. Gynaecol Endosc 11:327-329

10. Brölmann HAM, Oei SG (2000) The laparoscopic approach of transabdominal cerclage of the uterine cervix in case of cervical incompetence. Gynaecol Endosc 9:191-194

11. Ind T, Mason P (2000) Endoscopic trans-abdominal cervical cerclage. Gynaecol Endosc 9:199-200

12. Lessor KB, Childers JM, Surwit EA (1998) Transabdominal cerclage: a laparoscopic approach. Obstet Gynecol 91:855-856 